\title{
Díez Navarro, Ma. C. (2021). Abus. Iglú
}

\section{Gonzalo Maldonado-Ruiz*}

Recibido: 3 de enero de 2022 Aceptado: 25 de enero de 2022 Publicado: 31 de enero de 2022

To cite this article: Maldonado-Ruiz, G. (2022). Díez Navarro, Mª C. (2021). Abus. Iglú. Márgenes, Revista de Educación de la Universidad de Málaga, 3(1), 190-192

DOI: http://dx.doi.org/10.24310/mgnmar.v3i1.14056

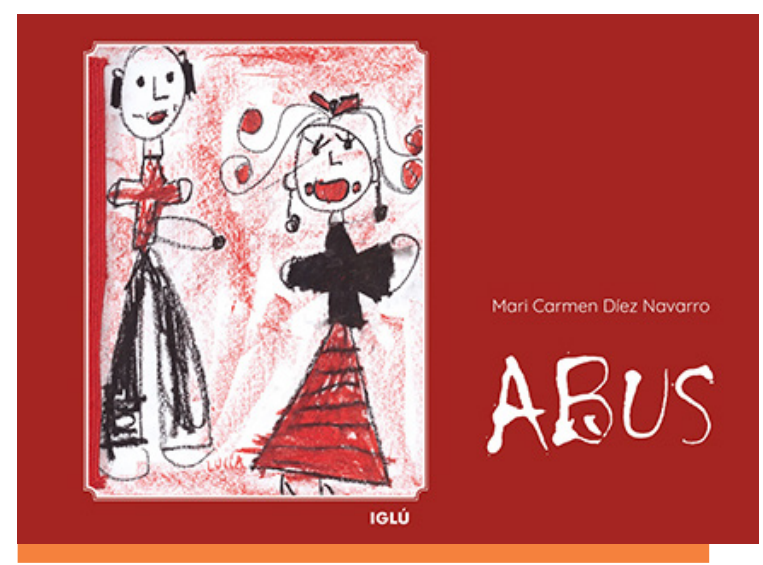

Abus (2021). Mari Carmen Díez Navarro. Editorial Iglú. 64 páginas. ISBN: 978-84-18488-18-4.

\begin{abstract}
RESUMEN
Esta es la reseña de una obra donde Mari Carmen Díez, maestra y autora admirada por la comunidad pedagógica, se abre para dejarnos descubrir sus vivencias y peripecias como abuela de Liam y Noah. Abus (2021) se convierte así en un epistolario poético cuya lectura, como se podrá ver en las próximas líneas, me ha despertado no solo una enorme emoción, sino una profunda reflexión sobre lo que puede suponer este vínculo familiar.
\end{abstract}

Palabras clave: literatura; poesía; relación intergeneracional

\section{ABSTRACT}

This is the review of a book by Mari Carmen Díez. This teacher and author admired by the pedagogical community opens up to let us discover her experiences and adventures as Liam and Noah's grandmother. Abus (2021) thus becomes a poetic epistolary whose reading has particularly moved me and made me reflect deeply on what this family bond can entail.

Keywords: literature; poetry; inter-generational relations

“QQué cosas tan raras hacemos los abuelos!” (p. 11), exclama Mari Carmen Díez Navarro en las pocas líneas en prosa que componen este viaje emocional y familiar llamado Abus (2021). No es baladí que comience por ese punto de partida porque, si bien cada cierto tiempo surgen relatos que ensalzan y agradecen la figura de las abuelas y los abuelos desde el lugar de las nietas y nietos, no es tan común poder entrar en diálogo con la vivencia en primera persona de quien un día comienza a ser nominada como tal. En otras palabras, la autora se presenta en esta obra como una abuela grande que, 
como "sí tiene risa, por eso usa versos sin prisa" (p. 17). Así decide escribir un epistolario con poemas dedicado a sus nietos Liam (para quien inicialmente estaba concebido el libro) y Noah (que llegó cuando éste estaba organizado, pero con tiempo suficiente para incluir creaciones dedicadas a él).

Por esta razón, el libro se divide en tres secciones fundamentales: La primera, “Abuelos y nietos", donde Mari Carmen va despertando nuestra sensibilidad e interés hacia esta relación de amor incondicional; la segunda, "A mi nieto Liam”, y la tercera, "A mi nieto Noah”, con poemas donde va rescatando aquellos momentos, palabras y caricias que emergen en forma de verso del encuentro abuela-nietos. Unos poemas que, además, acompaña con pequeños textos en prosa donde nos detalla aún más cómo eran esas escenas que escoge y por qué se encarnan de una manera tan imborrable en su biografía.

Además, todos estos textos van acompañados por ilustraciones realizadas por niñas y niños que, más allá de ser un mero complemento a las palabras de la autora, favorecen un encuentro estético entre su mirada de abu y la expresión subversiva de las infancias que, como en tantas otras ocasiones, entra en este libro para dar forma y color a lo sutil, lo común, lo que suele pasar desapercibido a nuestra mirada adulta.

Somos cómplices así del desarrollo de una historia de amor que nace incluso antes de que Liam llegara al mundo, puesto que Mari Carmen ya se reconoce antes como una abuela que está a la espera y que, aunque se pregunta incesantemente cómo será aquel que llega, le declara de manera tajante su disposición a querer: "Sea como sea, será un abrazo" (p. 31). El modo en el que la autora expresa esta "incondicionalidad" me resulta especialmente conmovedor porque el vínculo que ella quiere expresar se aleja de unas expectativas pre-fijadas para la vida de su nieto, es más, se asienta en la convicción de que sea como sea esta, será susceptible de su acompañamiento. Quizás deberíamos preguntarnos: ¿Es esta una disposición que todas y todos acogemos con facilidad? Y es que quizá, una vez entregadas y entregados al otro en los terrenos del amor (o de estos "cambalaches de abuela", como los nombra Mari Carmen) hablar en términos de facilidad resulta totalmente ajeno. Así, vamos conociendo a una abuela que quiere por encima de los artificios, que quiere desde la trastienda, hasta tal punto de aprovechar que Liam duerme (cuando no puede ser vista) para acudir a recuperar una cocinita tirada y enjabonarla para sorprenderle.

Pese a toda su entrega y disposición, su abrazo a la incertidumbre de quienes construyen su identidad le hace partir desde la incógnita de si sus nietos le querrán. De hecho, comparte su gozo al recibir un enorme beso de Noah que la dejaba "maravillada, al ver que, según todos los indicios... parece que empieza a quererme" (p. 53). La capacidad de asombro de esta abuela es precisamente la que le permite rescatar todos estos acontecimientos de lo cotidiano. Y ahí creo que trasciende otro valor identitario de la relación que se entreteje en sus líneas. Me resuena aquí una imagen de sus nietos como portadores de la novedad similar a la concepción arendtiana de infancia. Da igual que conozca cuál puede ser el proceso de desarrollo de las niños y los niños, da igual que haya tenido una dilatada experiencia como maestra que le permita prever ciertas respuestas, o da igual que Liam haya abierto el camino de una relación que después transitaría Noah. Eso, a la luz de sus palabras, no ha permitido que el estupor ante un abrazo, un enfado o un concierto de la banda del pueblo se vuelva anodino. 
La manera que encuentra Mari Carmen para provocar un eco en quien lee es a través de unos versos sencillos de corta extensión, de cuya musicalidad podemos disfrutar tanto las personas adultas como los niños y las niñas. Incluso, en el ámbito educativo, me atrevería decir que como maestro me resultaría muy interesante conocer cómo estos poemas resuenan en la cultura infantil y qué diálogos podrían emanar de ellos.

Más allá de todo lo mencionado, he de confesar que para un maestro de Educación Infantil que ya admiraba profesionalmente a Mari Carmen, Abus me ha permitido conocerla y casi apreciarla más. Pero, además, para alguien que, por cuestiones de la vida, no ha podido vivir esa relación intergeneracional de tal belleza, estas páginas me han supuesto un profundo impacto emocional al conocer ese tipo de amor que esta abuela grande destila en sus palabras y que, lejos de aferrarse al presentismo que podría suponer la dependencia de la fragilidad infantil, se abona a la incertidumbre que supone el crecimiento y el posible desapego de su figura:

"Has crecido esta noche y aún no me lo creo.

Y aún espero verte, y compararnos,

y encontrarte distinto" (p.62)

Ojalá, dentro de unos años, podamos conocer cuál es la respuesta que Liam y Noah tienen a esta preciosa carta de amor. Aunque pensándolo mejor, esto es más un deseo de lector, ya que Mari Carmen probablemente no espere esa respuesta, ya que el diálogo más importante de sus vidas lo ha vivido en su relación cotidiana en el cuerpo a cuerpo. 